\title{
Demand-side interventions for maternal care: evidence of more use, not better outcomes
}

Taylor E. Hurst ${ }^{1 *}$, Katherine Semrau ${ }^{2,3}$, Manasa Patna ${ }^{4,5}$, Atul Gawande $2,5,6$ and Lisa R. Hirschhorn 2,3,7

\begin{abstract}
Background: Reducing maternal and neonatal mortality is essential to improving population health. Demand-side interventions are designed to increase uptake of critical maternal health services, but associated change in service uptake and outcomes is varied. We undertook a literature review to understand current evidence of demand-side intervention impact on improving utilization and outcomes for mothers and newborn children.

Methods: We completed a rapid review of literature in PubMed. Title and abstracts of publications identified from selected search terms were reviewed to identify articles meeting inclusion criteria: demand-side intervention in low or middle-income countries (LMIC), published after September 2004 and before March 2014, study design describing and reporting on $>1$ priority outcome: utilization (antenatal care visits, facility-based delivery, delivery with a skilled birth attendant) or health outcome measures (maternal mortality ratio (MMR), stillbirth rate, perinatal mortality rate (PMR), neonatal mortality rate (NMR)). Bibliographies were searched to identify additional relevant papers. Articles were abstracted using a standardized data collection template with double extraction on a sample to ensure quality. Quality of included studies was assessed using McMaster University's Quality Assessment Tool from the Effective Public Health Practice Project (EPHPP).
\end{abstract}

Results: Five hundred and eighty two articles were screened with 50 selected for full review and 16 meeting extraction criteria (eight community mobilization interventions (CM), seven financial incentive interventions (FI), and one with both). We found that demand-side interventions were effective in increasing uptake of key services with five $\mathrm{CM}$ and all seven $\mathrm{Fl}$ interventions reporting increased use of maternal health services. Association with health outcome measures were varied with two studies reporting reductions in MMR and four reporting reduced NMR. No studies found a reduction in stillbirth rate. Only four of the ten studies reporting on both utilization and outcomes reported improvement in both measures.

Conclusions: We found strong evidence that demand-side interventions are associated with increased utilization of services with more variable evidence of their impact on reducing early neonatal and maternal mortality. Further research is needed to understand how to maximize the potential of demand-side interventions to improve maternal and neonatal health outcomes including the role of quality improvement and coordination with supply-side interventions.

Keywords: Demand-side, Community mobilization, Financial incentives, Maternal mortality, Infant mortality, Quality improvement, Maternal care

\footnotetext{
* Correspondence: taylor.hurst@mail.harvard.edu

${ }^{1}$ Department of Global Health and Population, Harvard School of Public

Health, 677 Huntington Avenue, Boston, MA, USA

Full list of author information is available at the end of the article
} 


\section{Background}

Maternal mortality results in approximately 800 deaths every day [1]. In 2013, 289,000 women died from potentially preventable causes during pregnancy and childbirth, and $99 \%$ of these deaths occurred in low and middle-income countries (LMIC) [1]. Since 1990, there has been a $45 \%$ reduction in maternal mortality; however, limited access to quality routine and emergency care during pregnancy and delivery leaves a large number of women at risk of preventable death [2].

There are a number of factors that contribute to maternal and early neonatal mortality. The three delays model proposes that mortality can be largely attributed to a 1) delay in the decision to seek care, 2) delay in arrival at a health facility, and 3) delay in the provision of care [3]. Increasing the uptake and quality of facilitybased maternal care in resource-limited settings is critical to achieving the goals of reducing maternal and early neonatal mortality. Interventions have included those focused on improving the quality and reach of services (supply) and those focused on increasing uptake (demand). Demand-side barriers hinder a woman's choice to seek or ability to reach accessible, high quality care, including: lack of information about services/providers, perceived quality of services, direct and indirect costs, discrimination (religious, political, ethnic), household and community preferences, and decision-making autonomy $[4,5]$. Demand-side interventions are designed to increase uptake through financial incentives that reduce the cost of accessing services or through community mobilization efforts to improve knowledge about available services and address cultural attitudes which may prevent uptake of potentially life-saving services [4]. This increase in uptake is a critical step in the path to reduce maternal and neonatal harm.

We conducted a review of published research and evaluations to explore the evidence supporting demandside interventions on increasing uptake of key services and reducing maternal and neonatal mortality.

\section{Methods}

A rapid search of PubMed was conducted using the following search terms:

"Health Services Needs and Demand"[majr] OR "Maternal Health Services/economics"[mesh] OR "Community Networks"[mesh] OR "Health Promotion"[Mesh] OR "Patient-Centered Care"[mesh] OR demand side[tiab] OR supply side[tiab] OR community mobili*[tiab] OR community engagement[tiab] OR patient cent*[tiab] OR voucher*[tiab] OR financial incentiv*[tiab] OR cash*[tiab] OR cash transfer[tiab] AND ("infant mortality"[mesh] OR infant mortality[tiab] OR neonatal mortality[tiab] OR perinatal mortality[tiab] OR peri natal mortality[tiab] OR infant death*[tiab] OR neonatal death*[tiab] OR perinatal death*[tiab] OR peri natal death*[tiab]) OR "Maternal Mortality"[Mesh] OR maternal mortalit*[tiab] OR maternal death*[tiab]

Titles were reviewed for potential relevance and abstracts of selected articles were read to identify studies for full review. To be included in the final data abstraction, the article needed to describe a demand-side intervention implemented in a low or middle-income setting, be published after September 2004 and before March 2014, describe study design (randomized controlled trial, pre-post, quasi-experimental), and report on at least one of the following outcomes: either an utilization outcome (antenatal care (ANC) visits, facility-based delivery, delivery with a skilled birth attendant) or a health outcome measure (maternal mortality ratio (MMR), stillbirth rate, perinatal mortality rate (PMR), neonatal mortality rate (NMR)).

Demand-side interventions were defined as interventions designed to increase utilization of maternal health services either through financial incentives (cash transfers, vouchers) or through the provision of information by participatory women's groups or other communitybased education efforts. Efforts to increase or improve service delivery in the community through interventions such as task-shifting or mobile clinics were considered supply-side interventions and not included. Purely qualitative studies, reviews, study protocols without results, and studies that included supply-side interventions were also excluded.

Bibliographies from relevant reviews were searched for additional studies, which were then added to the literature review. Because all identified studies were conducted in low or middle-income countries, no geographic limitations were added to the search terms. Study quality of the 16 studies included in the final review was assessed with McMaster University's Quality Assessment Tool from the Effective Public Health Practice Project (EPHPP) [6]. Data were extracted from all eligible articles using a standard data collection form to collect information about study design, interventions, and outcome measures (Table 1). The tool was tested by dual extraction of five articles by two authors (TH and LRH) to ensure consistency. The final data extraction was done by one author $(\mathrm{TH})$ with validation of identified areas of uncertainty by a second author (LRH). The completed data extraction was reviewed by two authors (LRH and MP).

\section{Results}

\section{Identified studies}

An initial search resulted in 582 articles (Fig. 1). Following review of titles and abstracts, 50 were selected for full review with 13 studies meeting criteria for extraction. Three additional studies [7-9] were identified from reviewing the references of the articles found in the search, resulting in 16 studies in the final analysis. Of 
Table 1 Description of studies included in the review

\begin{tabular}{|c|c|c|c|c|c|c|c|c|}
\hline Author & $\begin{array}{l}\text { Publication } \\
\text { Year }\end{array}$ & Country & Setting & Participants & Study Design & Eligibility Criteria & Intervention & Primary Outcomes \\
\hline \multicolumn{9}{|c|}{ Community Mobilization } \\
\hline Fottrell & 2013 & Bangladesh & Rural & 19,301 births & Cluster-RCT & $\begin{array}{l}\text { Women permanently } \\
\text { residing in the study area } \\
\text { who had a recorded birth } \\
\text { or pregnancy related death } \\
\text { in the final } 24 \text { months of } \\
\text { the intervention }\end{array}$ & $\begin{array}{l}\text { Monthly peer-facilitated } \\
\text { participatory action and } \\
\text { learning groups where } \\
\text { mothers discussed neonatal } \\
\text { and maternal health } \\
\text { problems and brainstormed } \\
\text { ideas to address them }\end{array}$ & NMR \\
\hline Hounton & 2009 & Burkina Faso & Rural & $\begin{array}{l}\text { Intervention: } 43,612 \text { women } \\
\text { Control: 52,126 women }\end{array}$ & Quasi-experimental & $\begin{array}{l}\text { Women aged } 12-49 \text { who } \\
\text { had been pregnant during } \\
\text { the survey reference period }\end{array}$ & $\begin{array}{l}\text { Community leaders led } \\
\text { structured meetings with } \\
\text { health professionals, } \\
\text { religious leaders, and } \\
\text { administrative officials to } \\
\text { identify barriers to care and } \\
\text { plan solutions }\end{array}$ & $\begin{array}{l}\text { Institutional births, NMR, } \\
\text { MMR }\end{array}$ \\
\hline Lewycka & 2013 & Malawi & Rural & $\begin{array}{l}24 \text { intervention and control } \\
\text { clusters (Intervention: } 27,361 \\
\text { women Control: 28,570 } \\
\text { women) }\end{array}$ & Cluster-RCT & $\begin{array}{l}\text { Women of childbearing } \\
\text { age (10-49) that lived in } \\
\text { the study area }\end{array}$ & $\begin{array}{l}\text { Trained facilitators led } \\
\text { community based groups } \\
\text { to identify maternal and } \\
\text { child health problems and } \\
\text { solutions }\end{array}$ & $\begin{array}{l}\text { MMR, PMR, NMR, IMR } \\
\text { exclusive breastfeeding }\end{array}$ \\
\hline Manandhar & 2004 & Nepal & Rural & $\begin{array}{l}\text { Intervention clusters: } 14,884 \\
\text { participants } \\
\text { Control clusters: } 14,047 \\
\text { participants }\end{array}$ & Cluster-RCT & $\begin{array}{l}\text { Closed cohort of married } \\
\text { women of reproductive } \\
\text { age }(15-49) \text { who could } \\
\text { become pregnant }\end{array}$ & $\begin{array}{l}\text { Trained, local facilitators } \\
\text { led women's groups to } \\
\text { increase knowledge and } \\
\text { implement action for } \\
\text { change }\end{array}$ & NMR \\
\hline More & 2012 & Mumbai (India) & Urban (slums) & $\begin{array}{l}24 \text { Intervention \& control } \\
\text { settlements } 283,000 \text { total } \\
\text { population } 18,197 \text { births }\end{array}$ & Cluster-RCT & $\begin{array}{l}\text { Women of child bearing } \\
\text { age in intervention } \\
\text { settlement }\end{array}$ & $\begin{array}{l}\text { Series of } 26 \text { women's group } \\
\text { sessions led by facilitator to } \\
\text { increase knowledge } \\
\text { develop an implement } \\
\text { local strategies to address } \\
\text { identified priority issues }\end{array}$ & $\begin{array}{l}\text { Perinatal care, MMR, } \\
\text { extended perinatal } \\
\text { mortality }\end{array}$ \\
\hline Mushi & 2010 & Tanzania & Rural & 512 deliveries & Pre-post & $\begin{array}{l}\text { All deliveries that occurred } \\
\text { during the study period }\end{array}$ & $\begin{array}{l}\text { Safe motherhood promoters } \\
\text { led community groups and } \\
\text { conduct home visits with } \\
\text { pregnant women }\end{array}$ & Skilled birth attendance \\
\hline Persson & 2013 & Vietnam & Rural and urban & $\begin{array}{l}\text { Intervention: } 44 \text { communes } \\
\text { Control: } 46 \text { communes }\end{array}$ & Cluster-RCT & $\begin{array}{l}\text { Mother-newborn pairs in } \\
\text { districts with } N M R \geq 15 / 1000\end{array}$ & $\begin{array}{l}\text { Local facilitators led monthly } \\
\text { meetings with health } \\
\text { workers, health center staff, } \\
\text { and community members to } \\
\text { prioritize perinatal health } \\
\text { problems and solutions }\end{array}$ & NMR \\
\hline
\end{tabular}

clusters (Intervention: 27,361 age (10-49) that lived in

women Control: 28,570

Thervention clusters: 14,884 Cluster-RC

participants

Control clusters: 14,047

4 Intervention \& contro

512 deliveries

problems and solutions 
Table 1 Description of studies included in the review (Continued)

\begin{tabular}{|c|c|c|c|c|c|c|c|c|}
\hline Tripathy & 2010 & India & Rural & $\begin{array}{l}18 \text { intervention and } \\
\text { control cluster (18,775 } \\
\text { total births) }\end{array}$ & Cluster-RCT & $\begin{array}{l}\text { Women } 15-49 \text { years old } \\
\text { who had given birth } \\
\text { during the study period } \\
\text { and were residing in } \\
\text { project area }\end{array}$ & $\begin{array}{l}\text { Trained, local women } \\
\text { facilitated monthly meetings } \\
\text { using the participatory } \\
\text { learning and action cycle to } \\
\text { share information, identify } \\
\text { maternal and newborn health } \\
\text { problems, and collectively } \\
\text { design, implement, and } \\
\text { evaluate strategies to address } \\
\text { these problems }\end{array}$ & $\begin{array}{l}\text { NMR, maternal } \\
\text { depression scores }\end{array}$ \\
\hline \multicolumn{9}{|c|}{ Financial Incentives } \\
\hline Bellows & 2013 & Kenya & $\begin{array}{l}\text { Urban (informal } \\
\text { settlements) }\end{array}$ & 4362 women & Pre-post & $\begin{array}{l}\text { The 2005/06 data set } \\
\text { included all females aged } \\
12-54 \text { years old who were } \\
\text { registered in the longitudinal } \\
\text { NUHDSS and had a live birth } \\
\text { or stillbirth between January } \\
2004 \text { and December } 2005 . \\
\text { The second data set } \\
\text { included all females aged } \\
12-54 \text { who had given birth } \\
\text { in the last } 6 \text { months }\end{array}$ & $\begin{array}{l}\text { Eligible women could } \\
\text { purchase vouchers that } \\
\text { covered antenatal care, } \\
\text { facility-based delivery, and } \\
\text { postnatal care }\end{array}$ & $\begin{array}{l}\text { Delivery in a health } \\
\text { facility }\end{array}$ \\
\hline De Allegri & 2012 & Burkina Faso & Rural & 1934 women & Pre-post & $\begin{array}{l}\text { Women residing in the } \\
1050 \text { households in Nouna } \\
\text { Health District included in } \\
\text { the representative sample }\end{array}$ & $\begin{array}{l}\text { Women who presented for a } \\
\text { normal facility-based delivery } \\
\text { received an } 80 \% \text { subsidy, } \\
\text { women who presented for } \\
\text { complicated deliveries or } \\
\text { C-sections charged } \\
\text { proportionally higher rates }\end{array}$ & $\begin{array}{l}\text { Delivery in a health } \\
\text { facility }\end{array}$ \\
\hline Gupta & 2012 & India & Rural and urban & $\begin{array}{l}\text { Pre: } 3929 \text { women } \\
\text { Post: } 5604 \text { women }\end{array}$ & Pre-post & $\begin{array}{l}\text { All women who delivered at } \\
\text { the NSCB Medical College \& } \\
\text { Hospital of Jabalpur district } \\
\text { between August } 2003 \text { and } \\
\text { August 2007. All pregnant } \\
\text { women were eligible to } \\
\text { receive the JSY cash incentive } \\
\text { if they chose to deliver in a } \\
\text { facility }\end{array}$ & $\begin{array}{l}\text { Provided antenatal and } \\
\text { postnatal services as well as a } \\
\text { cash incentive for mothers } \\
\text { after they delivered in a } \\
\text { government or accredited } \\
\text { private health facility }\end{array}$ & $\begin{array}{l}\text { Maternal mortality and } \\
\text { maternal morbidity }\end{array}$ \\
\hline Ir & 2010 & Cambodia & Rural & 2725 women & Quasi-experimental & $\begin{array}{l}\text { Pregnant women who } \\
\text { received vouchers and had } \\
\text { a facility-based delivery in } \\
\text { the three districts where the } \\
\text { program was implemented }\end{array}$ & $\begin{array}{l}\text { Women received vouchers for } \\
\text { antenatal visits, facility-based } \\
\text { deliveries, and postnatal care } \\
\text { as well as funds for } \\
\text { transportation costs. Health } \\
\text { Equity Fund schemes were also in } \\
\text { place to promote access to } \\
\text { health services for the poor }\end{array}$ & $\begin{array}{l}\text { Proportion of facility- } \\
\text { based deliveries }\end{array}$ \\
\hline
\end{tabular}


Table 1 Description of studies included in the review (Continued)

\begin{tabular}{|c|c|c|c|c|c|c|c|c|}
\hline Lim & 2010 & India & Rural and urban & 182,869 women & Quasi-experimental & $\begin{array}{l}\text { Women } 15-44 \text { years old } \\
\text { included in the DLHS } \\
\text { survey }\end{array}$ & $\begin{array}{l}\text { Women received a financial } \\
\text { incentive after delivering in } \\
\text { a government or accredited } \\
\text { private health facility }\end{array}$ & $\begin{array}{l}\text { Perinatal death, neonatal } \\
\text { death, MMR }\end{array}$ \\
\hline Nguyen & 2012 & Bangladesh & Rural and urban & $\begin{array}{l}16 \text { intervention \& comparison } \\
\text { sub-districts (1 } 104 \text { women in } \\
\text { each) }\end{array}$ & Quasi-experimental & $\begin{array}{l}\text { Women who had delivered } \\
6 \text { months prior to the survey }\end{array}$ & $\begin{array}{l}\text { Women received money for } \\
\text { transport costs and vouchers } \\
\text { for antenatal care, safe } \\
\text { delivery care in a facility or } \\
\text { at home, emergency care } \\
\text { for obstetric complications, } \\
\text { and postnatal care. After } \\
\text { delivery with a qualified } \\
\text { provider women also } \\
\text { received a cash incentive and } \\
\text { gift box }\end{array}$ & $\begin{array}{l}\text { ANC visits, institutional } \\
\text { delivery, delivery } \\
\text { attended by a qualified } \\
\text { provider (facility or at } \\
\text { home), incidence of } \\
\text { C-section, incidence of } \\
\text { PNC check-ups with a } \\
\text { qualified provider }\end{array}$ \\
\hline Randive & 2013 & India & Rural and urban & $\begin{array}{l}284 \text { districts (population } \\
1.7 \text { million) }\end{array}$ & Pre-post & $\begin{array}{l}\text { Population-based national } \\
\text { level surveys containing } \\
\text { maternal mortality and } \\
\text { birth data }\end{array}$ & $\begin{array}{l}\text { Women received a financial } \\
\text { incentive after delivering in } \\
\text { a government or accredited } \\
\text { private health facility }\end{array}$ & MMR, institutional births \\
\hline Barber & 2009 & Mexico & Rural & $\begin{array}{l}\text { Intervention: } 712 \text { births } \\
\text { Control: } 180 \text { births }\end{array}$ & $\mathrm{RCT}$ & $\begin{array}{l}\text { Women eligible for } \\
\text { Oportunidades (low-income } \\
\text { household in a marginalized } \\
\text { community) who lived in the } \\
\text { treatment or control } \\
\text { communities, had a singleton } \\
\text { live birth between } 1997 \text { and } \\
\text { 2003, and who received and } \\
\text { reported on ONC }\end{array}$ & $\begin{array}{l}\text { Households received a cash } \\
\text { transfer if a woman attended } \\
\text { educational programming } \\
\text { and completed a prescribed } \\
\text { prenatal care plan (\% ANC } \\
\text { visits and nutritional } \\
\text { supplements) }\end{array}$ & $\begin{array}{l}\text { Overall quality of care } \\
\text { score, quality scores } \\
\text { within three domains } \\
\text { (history taking and } \\
\text { diagnostics, physical } \\
\text { examination, and } \\
\text { prevention) }\end{array}$ \\
\hline
\end{tabular}




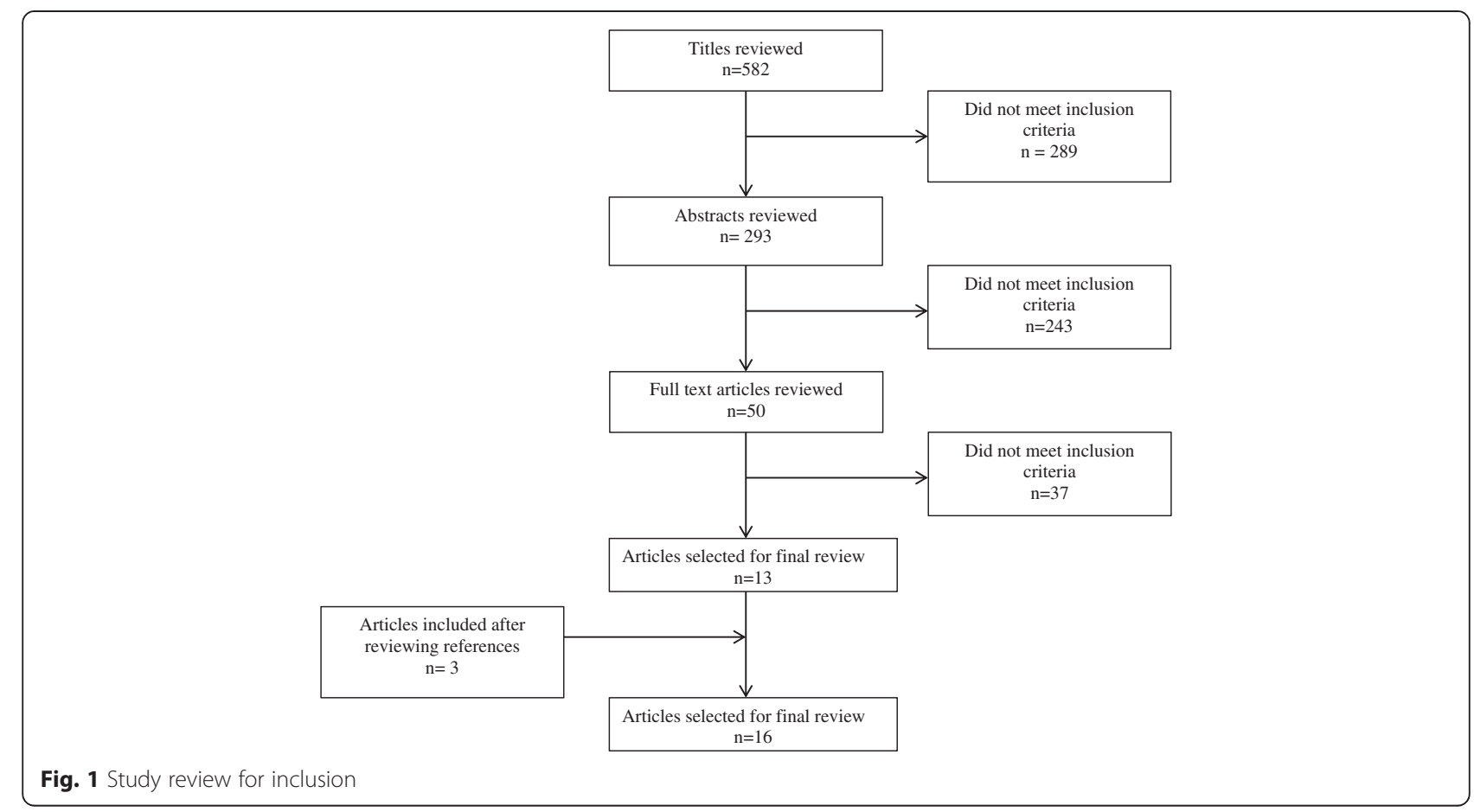

these 16 studies, eight described community mobilization interventions, seven reported on financial incentive interventions, and one intervention included both financial incentives and community mobilization. Community mobilization interventions included participatory women's groups, training of community facilitators, and community level health promotion. Financial incentive interventions included voucher schemes and conditional cash transfers, which involve the provision of money to a household or individual if specific, pre-determined conditions are met [10]. Interventions were implemented across a range of low and middle-income countries including: Bangladesh, Burkina Faso, Malawi, Cambodia, Kenya, Tanzania, Nepal, India, Vietnam, and Mexico. Nine of the interventions were implemented in rural settings, two in urban settings, and five spanned both rural and urban settings (Table 1).

Of the 16 final articles selected, seven were randomized controlled trials, five were pre-post studies, and four were quasi-experimental study designs. When assessed using McMaster University's Quality Assessment Tool, individual studies ranged in quality from 1 (strong) to 3 (weak). The overall average of study quality was 2.375 . Outcomes measured varied between studies and included both utilization measures (antenatal care (ANC), facility-based delivery, delivery with a skilled birth attendant) and health outcome measures (maternal mortality ratio (MMR), stillbirth rate, neonatal mortality rate (NMR), perinatal mortality rate (PMR)).

\section{Effectiveness of interventions \\ Utilization measures}

ANC visits, facility-based delivery, and delivery with a skilled birth attendant were included as service uptake measures in the extraction. Associations between demandside interventions and utilization measures were found in a number of studies (Table 2). There were 11 studies that measured uptake of ANC, seven community mobilization interventions, three financial incentive interventions, and one with both CM and FI interventions. Eight out of the eleven (72\%) studies reported an increase in antenatal care utilization, including four of the seven community mobilization studies, all three of the financial incentive studies, and the one study reporting a combination intervention (Table 3) [9, 11-13]. For example, in rural Mexico, pregnant women who were beneficiaries of Oportunidades received a cash transfer conditional on attending five antenatal care visits, taking nutritional supplements, and participating in monthly meetings led by beneficiary representatives to discuss prenatal care, nutrition, and reproductive health information. Beneficiaries of the program reported receiving $12.2 \%$ more antenatal care services than non-beneficiaries [5].

Fourteen studies measured change in facility-based delivery. These included seven community mobilization interventions and seven financial incentive interventions. Nine out of the 14 (64\%) reported an increased likelihood of a facility-based delivery associated with the intervention. These included two $[12,14]$ of the seven community mobilization interventions and all seven $[8,15-20]$ of the 
Table 2 Results by type of demand-side intervention

\begin{tabular}{|c|c|c|c|c|c|c|c|}
\hline \multicolumn{8}{|c|}{ Community mobilization } \\
\hline & Maternal mortality ratio & Stillbirth rate & Perinatal mortality rate & Neonatal mortality rate & Antenatal care & Facility-based delivery & Skilled birth attendance \\
\hline Fottrell & NS & NS & NS & ARR: $0.62(0.43,0.89)$ & NS & NS & NS \\
\hline Hounton & NS & - & OR: $0.75(0.70,0.80)$ & - & - & $30 \%$ increase & - \\
\hline Lewycka & AOR: $0 \cdot 51(0 \cdot 26-0 \cdot 99)$ & - & NS & NS & $\begin{array}{l}\text { Any ANC at health facility } \\
\text { AOR: } 1.50(1.03 \text { to } 2.19)\end{array}$ & NS & NS \\
\hline Manandhar & AOR: $0.22(0.05-0.90)$ & NS & - & AOR: 0.70 (0.53-0.94) & $\begin{array}{l}\text { Any ANC } \\
\text { AOR: } 2 \cdot 82(1.41-5.62)\end{array}$ & AOR: $3 \cdot 55(1 \cdot 56-8 \cdot 05)$ & $\begin{array}{l}\text { Doctor, nurse, or midwife } \\
\text { AOR: } 3 \cdot 53(1 \cdot 54-8 \cdot 10)\end{array}$ \\
\hline More & - & NS & NS & AOR: $1.48(1.06,2.08)$ & NS & NS & - \\
\hline Mushi & - & - & - & - & $\begin{array}{l}\text { Early ANC booking increase } \\
\text { from } 18.7 \text { to } 56.9 \%, p<0.001\end{array}$ & - & $\begin{array}{l}\text { Increase in SBA from } 34.1 \\
\text { to } 51.4 \% \text {, } \\
p<0.05\end{array}$ \\
\hline Persson & - & - & - & NS & AOR: $2.27(1.07-4.80)$ & NS & - \\
\hline Tripathy & NS & NS & AOR: $0.79(0.69,0.91)$ & AOR: $0 \cdot 68(0 \cdot 59-0 \cdot 78)$ & NS & NS & NS \\
\hline \multicolumn{8}{|c|}{ Financial incentives } \\
\hline & Maternal mortality ratio & Stillbirth rate & Perinatal mortality rate & Neonatal mortality rate & Antenatal care & Facility-based delivery & Skilled birth attendance \\
\hline \multirow[t]{2}{*}{ Bellows } & - & - & - & - & Any ANC visit: OR: 16.5 (4.0-68.1) & OR: $1.4(1.2-1.6)$ & OR: $1.2(1.1-1.4)$ \\
\hline & & & & & 4 + ANC visits: OR: 1.9 (1.6-2.4) & & \\
\hline De Allegri & - & - & - & - & - & Increase from 49 to $84 \%(p<0.001)$ & - \\
\hline Gupta & $\begin{array}{l}\text { Increased (1985 to } 2444 \\
\text { per 100,000 live births) }\end{array}$ & - & - & - & - & $42.6 \%$ increase in FBD & - \\
\hline Ir & - & - & - & - & - & $\begin{array}{l}\text { Increase in FBD from } 16.3 \text { to } 44.9 \% \\
\text { of the expected number of births } \\
\text { (2.4 to } 7 \% \text { for voucher recipients, } \\
58.1 \text { to } 69.8 \% \text { for Health Equity } \\
\text { Fund recipients) }\end{array}$ & - \\
\hline Lim & NS & - & $-3.7(-5.2,-2.2)$ & $-2.3(-3.7,-0.9)$ & 3 ANC visits: $10.7 \%$ (9.1 to 12.3$)$ & $43.5 \%$ (42.5 to 44.6 ) increase in FBD & $\begin{array}{l}36.6 \% \text { ( } 35.6 \text { to } 37.7) \\
\text { increase in SBA }\end{array}$ \\
\hline \multirow[t]{5}{*}{ Nguyen } & - & - & - & - & Cross sectional difference & $\begin{array}{l}37.5 \% \text { in intervention vs. } 18.7 \% \text { in } \\
\text { comparison areas, } p<0.001\end{array}$ & $\begin{array}{l}63.7 \% \text { in intervention vs. } \\
27.1 \% \text { in comparison areas, } \\
p<0.001\end{array}$ \\
\hline & & & & & $\begin{array}{l}\text { Any ANC check-up: } 91.6 \% \text { vs. } \\
75.6 \%, p<0.001\end{array}$ & & \\
\hline & & & & & $\geq 3$ ANC check-ups 0.241 & & \\
\hline & & & & & $54.8 \%$ vs. $33.6 \%, p<0.001$ & & \\
\hline & & & & & $\begin{array}{l}\geq 1 \text { ANC visit with qualified } \\
\text { provider } 79.2 \% \text { vs. } 54.9 \% \text {, } \\
p<0.001\end{array}$ & & \\
\hline
\end{tabular}


Table 2 Results by type of demand-side intervention (Continued)

\begin{tabular}{|c|c|c|c|c|c|c|c|}
\hline Randive & NS & - & - & - & - & $\begin{array}{l}\text { Increase from } 20 \text { to } 49 \% \text {, } \\
p<0.05\end{array}$ & - \\
\hline \multicolumn{8}{|l|}{ Both } \\
\hline & Maternal mortality ratio & Stillbirth rate & Perinatal mortality rate & Neonatal mortality rate & Antenatal care & Facility-based delivery & Skilled birth attendance \\
\hline Barber & - & - & - & - & $\begin{array}{l}12.2 \% \text { increase in number of } \\
\text { recommended ANC procedures } \\
\text { received }\end{array}$ & - & - \\
\hline
\end{tabular}

NS not significant ( $\mathrm{p}$-value $>0.05$ ), ARR adjusted risk ratio, $O R$ odds ratio, AOR adjusted odds ratio, MMR maternal mortality ratio, PMR perinatal mortality rate, NMR neonatal mortality rate, IMR infant mortality, ANC antenatal care, $F B D$ facility-based delivery, $S B A$ skilled birth attendance 
Table 3 Aggregation of results of community mobilization and financial incentive interventions for utilization and health outcome measures

\begin{tabular}{|c|c|c|}
\hline Utilization measures & Increase & No significant effect or decrease \\
\hline \multicolumn{3}{|l|}{ Antenatal care } \\
\hline$N=11(7 \mathrm{CM}, 3 \mathrm{Fl}, 1 \mathrm{~B})$ & $N=8(4 \mathrm{CM}, 3 \mathrm{Fl}, 1 \mathrm{~B})$ & $N=3(3 \mathrm{CM})$ \\
\hline \multicolumn{3}{|l|}{ Facility-based delivery } \\
\hline$N=14(7 \mathrm{CM}, 7 \mathrm{FI})$ & $N=9(2 \mathrm{CM}, 7 \mathrm{Fl})$ & $N=5(5 \mathrm{CM})$ \\
\hline \multicolumn{3}{|l|}{ Skilled birth attendant } \\
\hline$N=8(5 \mathrm{CM}, 3 \mathrm{FI})$ & $N=5(2 \mathrm{CM}, 3 \mathrm{Fl})$ & $N=3(3 \mathrm{CM})$ \\
\hline Health outcome measures & Decrease & No significant effect or increase \\
\hline \multicolumn{3}{|l|}{ Maternal mortality ratio } \\
\hline$N=8(5 \mathrm{CM}, 3 \mathrm{FI})$ & $N=2(2 \mathrm{CM})$ & $N=6(3 \mathrm{CM}, 3 \mathrm{FI})$ \\
\hline \multicolumn{3}{|l|}{ Stillbirth rate } \\
\hline$N=4(4 \mathrm{CM})$ & None & $N=4(4 \mathrm{CM})$ \\
\hline \multicolumn{3}{|l|}{ Perinatal mortality rate } \\
\hline$N=6(5 \mathrm{CM}, 1 \mathrm{FI})$ & $N=3(2 \mathrm{CM}, 1 \mathrm{Fl})$ & $N=3(3 \mathrm{CM})$ \\
\hline \multicolumn{3}{|l|}{ Neonatal mortality rate } \\
\hline$N=7(6 \mathrm{CM}, 1 \mathrm{Fl})$ & $N=4(3 \mathrm{CM}, 1 \mathrm{Fl})$ & $N=3(3 \mathrm{CM})$ \\
\hline
\end{tabular}

financial incentive interventions that measured facilitybased delivery.

Eight studies measured change in deliveries conducted by a skilled birth attendant, including five community mobilization interventions and three financial incentive interventions. Five $(62.5 \%)$ out of eight total studies reported an increase in attended deliveries; two [12,13] of the five community mobilization interventions and all three $[8,17,18]$ of the financial incentive interventions.

Only four studies, one using a community mobilization intervention and three using financial incentives interventions, reported an increase across all three utilization indicators [8, 12, 17, 18]. Manandhar et al.'s study in rural Nepal used women's groups led by trained, local facilitators to increase knowledge, and engage participants in identifying local maternal and neonatal problems and implementing strategies to address them. Their findings included an increase in ANC (AOR: 2.82 (1.41-5.62)), facility-based delivery (AOR: 3.55 (1.56-8.05)), and deliveries by a doctor, nurse, or midwife (AOR: 3.53 (1.54-8.10)) [12]. Bellows et al. found that allowing eligible women in urban Kenya to purchase vouchers that covered antenatal care, facility-based delivery, and postnatal care also resulted in an increase in all three measures: ANC (OR: 16.5 (4.0-68.1)), facility-based delivery (OR: 1.4 (1.2-1.6)) and skilled birth attendance (OR: 1.2 (1.1-1.4)) [8]. Lim et al. described an increased probability of attending three antenatal care visits (10.7\%), having a facilitybased delivery (43.5\%), and giving birth with a skilled attendant $(36.6 \%)$ when a post-delivery financial incentive was provided to women in rural India as part of the national Janani Suraksha Yojana conditional cash transfer scheme [17]. In the fourth study conducted by Nguyen et al., Bangladeshi women received money for transport costs, vouchers for antenatal care, safe delivery at home or in a facility, emergency care for complications, postnatal care, plus a gift and cash incentive for delivery with a qualified provider. The women who received the intervention had a 13.6 percentage point increase in institutional delivery and 46.4 percentage point increase in use of a skilled provider during delivery when compared to women in the comparison sub-districts [18].

\section{Health outcome measures}

The association between demand-side interventions and health outcome measures was more varied. Eight studies measured MMR, five community mobilization and three financial incentive interventions. Only two studies (25\%), both community mobilization interventions, reported a drop in MMR $[11,12,14]$. Lewycka et al. found a drop in MMR (AOR: 0.51 (0.26-0.99)) associated with women's groups in Malawi when adjusting for parity, socioeconomic quintile, baseline measures [8] In contrast, Gupta et al. reported mixed results on maternal mortality in their study on the impact of Janani Suraksha Yojana (JSY) in India. The overall maternal mortality ratio increased from 1985 to 2444 per 100,000 live births in the study population. However, when MMR was analysed by subgroup, there was a significant decrease in maternal mortality among urban women (2456 to 1710 per 100,000 live births, $p<0.01$ ), an effect not seen in women from rural areas [14]. 
Four studies measured stillbirth rate, with none reporting a significant change after the implementation of a demand-side intervention. Six studies measured PMR, one using financial incentives and five using community mobilization interventions. Three of the six studies (50\%) reported a significant decrease in PMR, which included one [17] of the three studies using financial incentives and two $[14,21]$ of the three studies using community-focused efforts. Neonatal mortality ratio (NMR) was measured in seven studies, six on community mobilization interventions and one on financial incentives. Four (57\%) reported a decrease in NMR, including three community mobilization and one financial incentive intervention [12, $21,22]$. For example, Fottrell et al. reported a $38 \%$ reduction in the neonatal mortality rate (21.3 neonatal deaths per 1000 live births versus 30.1 per 1000 in control areas) after increasing coverage of community-based participatory action and learning groups [18]. The evaluation of India's Janani Suraksha Yojana conditional cash transfer program also found a reduction of $2.3(0.9-3.7)$ neonatal deaths per 1000 live births associated with JSY payment [17]. In contrast, More et al. reported an increase in NMR (AOR: $1.48(1.06,2.08)$ ) in their study of participatory women's groups in Mumbai [23].

\section{Combined utilization and health outcomes}

Ten studies reported on utilization and health outcome measures, seven community and three financial interventions. Four (40\%) of these studies reported both increased utilization and decreased mortality, including three $[9,11,13]$ of the seven community mobilization interventions and one [17] of the three financial incentive interventions. In rural Burkina Faso, Hounton et al. found a $30 \%$ increase in facility-based delivery and decrease in PMR (OR: 0.75 (0.70-0.80)) during a study of community-led meetings with key stakeholders including traditional leaders, health professionals, and religious leaders [14]. In rural Malawi, facilitator-led communitybased groups designed to identify maternal and child health problems and solutions were associated with both an increase in antenatal care (AOR: 1.50 (1.03-2.19)) and decrease in MMR (AOR: 0.51 (0.26-0.99)) [11]. Similarly, Manandhar et al. found that a participatory women's group in rural Nepal was associated with an increase in antenatal care, facility-based delivery, and skilled birth attendance as well as a decrease in the maternal mortality ratio and perinatal mortality rate [12]. An evaluation of JSY in India by Lim et al. also found improvements in the use of antenatal care, facility-based delivery, and skilled birth attendance and a decrease in perinatal and neonatal mortality at the district level [17].

This association between interventions and measured utilization and health outcomes was not always observed. Two community mobilization studies [21, 22] reported improved health outcomes without any significant changes in utilization and two studies (one each of financial incentives [19] and community mobilization [9]) reported increased utilization with no significant changes to maternal or infant mortality. One of the studies of JSY found an increase in facility-based deliveries simultaneous with an increased MMR in rural areas, and decreased MMR in urban areas [15].

\section{Discussion}

Our review of the literature published in the last decade found evidence that financial incentives and community mobilization interventions can be effective in increasing the uptake of key maternal health services, including ANC visits, facility-based delivery and delivery with a skilled birth attendant. This increase in utilization of facilitybased services is an important first step in reducing maternal and neonatal morbidity and mortality. These findings are largely consistent with existing reviews that have found an increase in health service utilization after the implementation of conditional cash transfer [24] and voucher programs [25].

The overall effect of demand-side interventions on health outcome measures was less clear than the results with increasing utilization of services. While there were four studies that reported both an increase in utilization and decrease in at least one mortality outcome, [11, 12, $14,17]$, another study on participatory women's groups showed a decrease in maternal and neonatal mortality despite no increase in utilization [26]. The authors of this study suggest that this seemingly contradictory finding reflects the complex mechanisms through which community mobilization may improve maternal and child health.

Similar heterogeneity of results was seen in a study on the large-scale financial incentive scheme in India which reported an increase in facility-based deliveries and drop in neonatal mortality, but no similar drop in maternal mortality [17]. The authors hypothesized that the decrease in NMR may have resulted from the encouragement of timely care seeking that shifted mortality from stillbirth to early neonatal death. These variable effects on health outcomes are consistent with a systematic review by Prost et al., which found a significant reduction in neonatal mortality but non-significant reductions in stillbirths and maternal mortality associated with participatory learning and action groups [27].

Only one quarter of the studies that measured MMR found a decrease, with reducing neonatal mortality an even greater challenge. The weak association between increased uptake of maternal health services and health outcome measures may be explained by the quality and effectiveness of care received in health facilities [28]. Poor quality care will not translate to better health outcomes even if there is increased utilization of services. 
For example, a study of India's Janani Suraksha Yojana program reported a $42.6 \%$ increase in facility-based delivery with a statistically significant increase in overall and rural MMR, but a significant decrease in urban MMR [15]. Further exploration is needed about whether worse quality care or weaker referral systems in rural versus urban facilities may account for the difference in mortality rates. Through a series of interviews with policy representatives of the National Rural Health Mission in India, Bhattacharyya et al. noted the challenges faced in providing quality facility-based care due to limited human resources, gaps in supplies and infrastructure and poor monitoring. Although the JSY program generated demand for services, limitations in infrastructure, human resources, supplies and equipment resulted in congestion and, in some cases, a deterioration of quality of care [29].

The variability in impact observed across studies highlights the need to understand and address the complete pathway from utilization to improved health outcomes including the potential benefits of combining demand-side with supply-side interventions targeting care once a woman reaches a facility. Poor quality of facility-based care has been identified as one of the factors contributing to maternal mortality and morbidity, highlighting the need to simultaneously increase utilization and invest in developing health systems that can offer quality care to meet the increased demand for services [30]. Other factors affecting maternal and neonatal health outcomes may include delays in care seeking, or underlying causes such as lack of education, poor water and sanitation, and malnutrition [31].

The intensity and coverage of demand-side interventions within a population may also affect whether changes in health outcomes are observed. Azad et al. found no statistically significant effects on health outcome measures or utilization of services with a community mobilization program in rural Bangladesh [32]. However, when this same intervention was increased in intensity from one women's group per 1414 population to a coverage of 1 women's group per 309 population, a $38 \%$ reduction in NMR in the intervention areas was seen compared to the control areas (ARR: $0.62(0.43$, 0.89)) [22]. This coverage threshold is consistent with the findings that a participatory learning and action model is a cost-effective strategy to improve maternal and neonatal survival when at least a third of pregnant women participate in the intervention [27].

Although increasing coverage of maternal health programs is important, focusing on "effective coverage" by listening to patients' reported quality of care received, ensuring adequacy of trained staff, infrastructure, supplies and equipment, and investing in patient records needs to be prioritized to ensure that the care women and their infants receive is effective and evidence-based $[33,34]$. In a study on maternal health care in Ghana, researchers found that despite increased coverage of free services, women who had negative experiences while seeking care such as overcrowding, delays, and substandard care were unlikely to seek further maternal health services [35]. Furthermore, an observational study by Chaturvedi et al., reported poor quality care in Indian health facilities under the JSY scheme. These findings underscore the importance of ensuring the availability of quality obstetric care prior to increasing demand for services. Perceptions of poor quality and experiences of care, including disrespectful treatment, have also been found to influence women's decision of whether to seek care. For example, in a study in rural Tanzania by Kruk et al., $40 \%$ of women who delivered in a facility bypassed their nearest facility. One of the reasons cited for this choice was perception of poor quality care [36].

More specifically, there needs to be a focus on improving comprehensive emergency care in order to improve maternal and child health outcomes [37]. Indicators for emergency obstetric care include measures of availability, geographical distribution of facilities, proportion of births in emergency facilities, ability to treat women with complications, caesarean sections and direct obstetric case fatality rate. Key functions such as administering parenteral antibiotics and performing basic neonatal resuscitation are included in the basic services that should performed, signalling the importance of investing in supply side interventions [38]. We do not have information for all studies regarding the specific services provided, or the quality of those services. A lack of technical quality of services available in health facilities may explain the gap between increases in demand and improved health outcomes. It is important for future studies on supply or demand-side interventions to collect information about the quality measures of services provided.

There are a number of limitations of this review. The settings of the studies varied widely in their national and local contexts. These include: the degree of urbanization, population and facility level targeted, existing health infrastructure, differences in geographical accessibility to services, community perceptions of the value of maternal health services and quality of existing facility-based care. These contextual factors are critical to the success of interventions and may limit the generalizability of some of the successful initiatives and explain the challenges of others. Because of the limited number of studies and the variability of both intervention design and context, we could not explore if the differences in measured change in health care uptake and outcome measures across interventions were due to the differences in intervention type, contextual factors or a combination of both.

Due to heterogeneity in intervention, study design, location, and outcomes measured, we were not able to combine results within the two categories to estimate overall 
intervention effect or draw conclusions on the relative effectiveness of community mobilization versus financial incentives. The majority of studies were set in India and Southeast Asian countries, so the ability to generalize across other key regions including Africa (three studies) and central and Latin America (one study) is also limited. More broadly, the use of health outcome measures such as maternal mortality ratio to detect impact may be limited by factors such as small numbers of maternal deaths, insufficient sample size, and quality of the mortality data available. Varying definitions of the outcome of interest may also impact the comparability of the results. Another limitation is the small proportion of studies that measure maternal and neonatal morbidity health outcomes. For every death that occurs, there are many more women who face long-term sequelae of pregnancy and childbirth. Understanding the impact of demand and supply side interventions on morbidity would give us a clearer picture of health outcomes.

It was also not possible to identify if the causes for variability in measured change in health outcome measures were due to the differences in intervention, contextual factors not reported (such as quality of care or presence of other demand or supply-side interventions active during the study period) or a combination of both. For example, there were varying models of community mobilization interventions. While they all aimed to facilitate a participatory learning model, there may have been variation in the facilitator or structure of community mobilization interventions, which may influence women's decision whether to seek services. Conclusions about the impact of financial incentives were also limited by the small number of published studies, with three of the seven from India evaluating the JSY national program.

Within interventions, our review was limited to those studies which were specifically targeted at increasing demand for facility-based maternal health services (antenatal and delivery care). Other approaches to reducing women's financial barriers to care in the context of broader financial reforms, such as health insurance schemes and financial interventions targeting non-facility-based care, are not explored in this study. As a result we may have missed the impact of broader insurance schemes as an effective strategy for increasing demand for maternal care. Although the articles that were included in this rapid review focused primarily on financial or knowledge barriers, we recognize that there may be other interventions in place to address the numerous barriers to maternal health services that did not meet our inclusion criteria or that may not be described in the peer-reviewed literature.

We only included studies that had undergone peerreview as a measure of methodological rigor, and, as a result, excluded reports of other demand-side interventions only available in the grey literature. During study selection we conducted an assessment of the quality of each of the studies using McMaster University's Quality Assessment Tool from the Effective Public Health Practice Project (EPHPP). There was a range of reporting rigor and study designs, resulting in variation of study quality (from 'weak' to 'strong') that may limit the conclusions able to be drawn. Our methods were also designed to only include quantitative studies in order to facilitate a rapid review. The exclusion of qualitative studies limits the understanding of mechanisms through which interventions did or did not change health care utilization or outcomes. Integration of qualitative studies into the rapid reviews process can highlight potential areas for strengthening the adaption and implementation of effective interventions in different contexts and improving tested ones, which fell short of their planned goals.

Due to resource constraints, two independent reviewers only did a sample of the abstractions, with one main reviewer completing the work. However, two of the investigators reviewed the final abstractions and provided input regularly throughout the study for any areas where consultation was needed.

We limited the review to only publications from the last 10 years, and while we may have missed some published studies, we chose to limit this to reflect a rapid review approach and focus on interventions which were from the same time period as the decline in maternal mortality seen in the last decade. Another limitation is the exclusion of relevant articles that have been published since the review was conducted in March 2014, which may have added evidence for or against the effectiveness of exclusively demand-side interventions on utilization and outcomes.

\section{Conclusions}

In conclusion, we found evidence that demand-side interventions using financial incentives or community mobilization can increase utilization of facility-based services for pregnant women with more varying evidence of impact on reducing early neonatal and maternal mortality. Further research is needed to understand the associated costs, potential for sustainability, and relative prioritization of these demand-side interventions compared with other approaches to increase uptake of these essential services for women and their newborn children. In addition, more work is needed to understand the contextual factors associated with the variable impact on maternal and neonatal mortality and the potential role of simultaneous investment in supply side factors, [4] such as staff, medical equipment and supplies, referral systems and quality of care delivered. Only by identifying and implementing locally adapted effective approaches which address gaps of demand and supply can we ensure that the growing number of women seeking facility-based care receive high 
quality maternal health services needed to reduce maternal and neonatal morbidity and mortality [26].

\section{Competing interests}

The authors declare that they have no competing interests.

\section{Authors' contributions}

LH conceived of the study, participated in the design of the methodology, carried out secondary data extraction, and helped draft the manuscript. $\mathrm{TH}$ conducted the PubMed literature search, performed initial data extraction, did primary data analysis and drafted the manuscript. KS provided feedback on the results and helped draft the manuscript. MP participated in the design of the methodology and provided feedback on the results and manuscript. AG provided intellectual guidance on the study design and reviewed and provided feedback on the manuscript. All authors read and approved the final manuscript.

\section{Acknowledgements}

This study was supported by funds from the John D. and Catherine T. MacArthur Foundation.

\section{Author details}

'Department of Global Health and Population, Harvard School of Public Health, 677 Huntington Avenue, Boston, MA, USA. ${ }^{2}$ Ariadne Labs, 401 Park Drive 3 East, Boston, MA, USA. ${ }^{3}$ Division of Global Health Equity, Brigham and Women's Hospital, Boston, MA, USA. ${ }^{4}$ Department of Obstetrics and Gynecology, Cambridge Health Alliance, Cambridge, MA, USA. ${ }^{5}$ Harvard Medical School, Boston, MA, USA. ${ }^{6}$ Department of Surgery, Brigham and Women's Hospital, Boston, MA, USA. ${ }^{7}$ Department of Global Health and Social Medicine, Harvard Medical School, Boston, MA, USA.

\section{Received: 11 June 2015 Accepted: 31 October 2015}

\section{Published online: 13 November 2015}

\section{References}

1. WHO. Maternal mortality. In: Fact sheets. N348th ed. 2014.

2. MDG5: improve maternal health. 2015. [http://www.who.int/topics/ millennium_development_goals/maternal_health/en/]

3. Thaddeus S, Maine D. Too far to walk: maternal mortality in context. In: Soc Sci Med, vol. 38. 1994. p. 1091-110.

4. Ensor T, Stephanie C. Overcoming barriers to health service access: influencing the demand side. Health Policy Plan. 2004;19(2):69-79.

5. Connell T, Bedfor K, Thiede M. McIntyre: Synthesizing qualitative and quantitative evidence on non-financial access barriers: implications for assesment at the distric level. Int J Equity Health. 2015;14:54.

6. Quality Assessment Tool for Quantitative Studies. 2009. [http:// www.ephpp.ca/index.html]

7. Barber SL, Gertler PJ. Empowering women to obtain high quality care: evidence from an evaluation of Mexico's conditional cash transfer programme. Health Policy Plan. 2009;24:18-25.

8. Bellows B, Kyobutungi C, Mutua MK, Warren C, Ezeh A. Increase in facility based deliveries associated with maternal health voucher programme in informal settlements in Nairobi, Kenya. Health Policy Plan. 2012;28:134-42.

9. Persson LA, Nguyen TN, Malqvist M. Effect of facilitation of local maternaland-newborn stakeholder groups on neonatal mortality: cluster-randomized controlled trial. PLoS Med. 2013;10(5):e1001445.

10. World Health Organization. Conditional cash transfer programmes and nutritional status. In: e-Library of Evidence for Nutrition Actions (eLENA). http://www.who.int/elena/titles/cash_transfer/en/.

11. Lewycka S, Mwansambo C, Rosato M, Kazembe P, Phiri T, Mganga A, et al. Effect of women's groups and volunteer peer counselling on rates of mortality, morbidity, and health behaviours in mothers and children in rural Malawi (MaiMwana): a factorial, cluster-randomised controlled trial. Lancet. 2013;381(9879):1721-35.

12. Manandhar DS, Osrin D, Shrestha BP, Mesko N, Morrison J, Tumbahangphe $\mathrm{KM}$, et al. Effect of a participatory intervention with women's groups on birth outcomes in Nepal: cluster-randomised controlled trial. Lancet. 2004;364(9438):970-9.

13. Mushi $D$, Mpembeni $R$, Jahn A. Effectiveness of community based safe motherhood promoters in improving the utilization of obstetric care.
The case of mtwara rural district in Tanzania. BMC Pregnancy Childbirth. 2010;10:14.

14. Hounton S, Byass P, Brahima B: Towards reduction of maternal and perinatal mortality in rural Burkina Faso: communities are not empty vessels. Glob Health Action. 2009, 2 doi: 10.3402/gha.v2i0.1947.

15. Gupta SK, Pal DK, Tiwari R, Garg R, Shrivastava AK, Sarawagi R, et al. Impact of Janani Suraksha Yojana on institutional delivery rate and maternal morbidity and mortality: an observational study in India. J Health Popul Nutr. 2012;30(4):464-71.

16. Ir P, Horemans D, Souk N, Van Damme W. Using targeted vouchers and health equity funds to improve access to skilled birth attendants for poor women: a case study in three rural health districts in Cambodia. BMC Pregnancy Childbirth. 2010;10:1

17. Lim SS, Dandona L, Hoisington JA, James SL, Hogan MC, Gakidou E. India's Janani Suraksha Yojana, a conditional cash transfer programme to increase births in health facilities: an impact evaluation. Lancet. 2010;375(9730):2009-23.

18. Nguyen HT, Hatt L, Islam M, Sloan NL, Chowdhury J, Schmidt JO, et al. Encouraging maternal health service utilization: an evaluation of the Bangladesh voucher program. Soc Sci Med. 2012;74(7):989-96.

19. Randive B, Diwan V, De Costa A. India's Conditional Cash Transfer Programme (the JSY) to Promote Institutional Birth: Is There an Association between Institutional Birth Proportion and Maternal Mortality? PLoS One. 2013:8(6):e67452.

20. De Allegri M, Ridde V, Louis VR, Sarker M, Tiendrebeogo J, Ye M, et al. The impact of targeted subsidies for facility-based delivery on access to care and equity - evidence from a population-based study in rural Burkina Faso. J Public Health Policy. 2012;33(4):439-53.

21. Tripathy P, Nair N, Barnett S, Mahapatra R, Borghi J, Rath S, et al. Effect of a participatory intervention with women's groups on birth outcomes and maternal depression in Jharkhand and Orissa, India: a cluster-randomised controlled trial. Lancet. 2010;375(9721):1182-92.

22. Fottrell E, Azad K, Kuddus A, Younes L, Shaha S, Nahar T, et al. The effect of increased coverage of participatory women's groups on neonatal mortality in Bangladesh: A cluster randomized trial. JAMA Pediatr. 2013;167(9):816-25.

23. More NS, Bapat U, Das S, Alcock G, Patil S, Porel M, et al. Community mobilization in Mumbai slums to improve perinatal care and outcomes: a cluster randomized controlled trial. PLoS Med. 2012;9(7):e1001257.

24. Lagarde M, Haines A, Palmer N. Conditional cash transfers for improving uptake of health interventions in low and middle income countries: a systematic review. JAMA. 2007;298(16):1900-10.

25. Bellows N, Bellows B. The use of vouchers for reproductive health services in developing countries: systematic review. Trop Med Int Health. 2011;16(1):84-96

26. WHO. Evidence and recommendation on community mobilization through facilitated participatory learning and action cycles with women's groups fro maternal and newborn health. 2014.

27. Prost A, Colbourn T, Seward N, Azad K. Women's groups practising participatory learning and action to improve maternal and newborn health in low-resources settings: a systematic review and meta-analysis. Lancet. 2013;381(9879):1736-46.

28. Ronsmans C, Graham W. Maternal Mortality: who, when, where, and why. Lancet. 2006;368(9542):1189-200.

29. Bhattacharyya S, Srivastava A, B.I. A, Graham WJ: Quality care at childbirth in the context of health sector reform program in India: Contributing factors, challenges, and implementation lesson. iMedPub J. 2012;1:1-8. http:// www.researchgate.net/publication/236866321_Quality_care_at_childbirth_ in_the_context_of_Health_Sector_Reform_Program_in_India_ Contributing_factors_Challenges_Implementation_.

30. Austin A, Langer A, Salam RA, Lassi ZS, Das JK, Bhutta ZA. Approaches to improve the quality of maternal and newborn health care: an overview of the evidence. Reprod Health. 2014;11 Suppl 2:S1.

31. UNICEF. Conceptual framework for maternal and neonatal mortality and morbidity. In. http://www.unicef.org/malaysia/SOWC09Conceptual_framework_Figure-1.7-EN.pdf.

32. Azad K, Barnett S. Effect of scaling up women's groups on birth outcomes in three rural districts in Bangladesh: a cluster randomized controlled trial. Lancet. 2010;375(9721):3-9.

33. Graham WJ, McCaw-Binns A, Munjanja S. Translating coverage gains into health gains for all women and children: The quality of care opportunity. PLoS Med. 2013;10(1):e1001368. 
34. Chaturvedi S, De Costa A, Raven J. Does the Janani Suraksha Yojana cash transfer programme to promote facility births in India ensure skilled birth attendance? A qualittive study of intrapartum care in Madhya Pradesh. Glob Health Action. 2015:8:27427.

35. Ganle JK, Parker M, Fitzpatrick R, Otupiri E. A qualitative study of health system barriers to accessibility and utilization of maternal and newborn healthcare services in Ghana after user-fee abolition. BMC Pregnancy Childbirth. 2014;14:425.

36. Kruck M, Mbaruku G, McCord C, Moran M, Rockers P, Galea S. Bypassing primary care facilities for childbirth: a population-based study in rural Tanzania. Health Policy Plan. 2009;24(4):279-88.

37. Souza JP, Gulmezoglo AM, Vogel J, Carroli G, Lumbiganon P. Moving beyond essential interventions for reduction of maternal mortality (the WHO Multicountry Survey on Maternal and Newborn Health): a cross sectional study. Lancet. 2013;381:279-88.

38. World Health Organization. Monitoring emergency obstetric care: A handbook. In. WHO: Switzerland; 2009.

\section{Submit your next manuscript to BioMed Central and take full advantage of:}

- Convenient online submission

- Thorough peer review

- No space constraints or color figure charges

- Immediate publication on acceptance

- Inclusion in PubMed, CAS, Scopus and Google Scholar

- Research which is freely available for redistribution 